\title{
RELAÇÕES DE INTIMIDADE JUVENIS E ADULTAS, UMA ANÁLISE COMPARATIVA: DAS NARRATIVAS DE AMOR ÀS CONJUGALIDADES VIOLENTAS ${ }^{1}$
}

\author{
Ana Rita Dias ${ }^{2}$ \\ Celina Manita ${ }^{3}$ \\ Rui Abrunhosa Gonçalves ${ }^{4}$ \\ Carla Machado 5
}

[Enviado a 14-08-2012. Aceite a 23-12-2012]

\begin{abstract}
Resumo: Neste estudo faz-se uma análise comparativa entre o discurso de participantes com história de violência nas relações de intimidade e o discurso de participantes sem história de violência, tanto na população juvenil como na população adulta. O estudo inclui 24 participantes com história de violência e 28 participantes sem história de violência, com os quais se conduziu uma entrevista individual sobre a história de amor da sua vida. Identificaram-se cinco repertórios interpretativos sobre o amor, partilhados por todos os participantes e verificaram-se diferenças no padrão de utilização e na amplitude dos repertórios. Discute-se de que forma os repertórios podem facilitar ou limitar a violência na intimidade. Por fim, considerando as especificidades identificadas no discurso das vítimas, dos agressores e dos jovens, discutimos potenciais pontos de intervenção para cada caso.
\end{abstract}

Palavras-chave: amor; violência; intimidade; repertórios interpretativos; cultura.

Young and adult intimate relationships, a comparative analysis: From narratives on love to violent conjugalities (Abstract): In this study we make a comparative

\footnotetext{
1 Trabalho financiado pela FCT no âmbito do projeto "Vitimação múltipla de mulheres socialmente excluídas: inserção de significados e trajectórias para a mudança" (PTCD/PSI - APL/1138885/2009.

2 Escola de Psicologia, Universidade do Minho, Bolseira de Investigação

${ }^{3}$ Faculdade de Psicologia e das Ciências da Educação, Universidade do Porto, Professora Associada

${ }^{4}$ Escola de Psicologia, Universidade do Minho, Professor Associado com Agregação

${ }^{5}$ Escola de Psicologia, Universidade do Minho, Professora Auxiliar
}

PSICOLOGIA, Vol. XXVII (1), 2013, Edições Colibri, Lisboa, pp. 63-89 
analysis between the discourse of participants with a history of violence in intimate relationships and the discourse of the participants without a history of violence, both in the youth population as in the adulthood. The study includes 24 participants with a history of violence and 28 participants without a history of violence, with who we conducted an individual interview about the love story of their lives. Five interpretative repertoires about love were identified in all participants, and we also found differences in the use pattern and in the range of the repertoires. We discuss how the participants use the interpretative repertoires to facilitate or limit the intimate violence. Finally, considering the specificities identified in the discourse of victims, offenders and young people, we discuss some potential intervention issues for each case.

Keywords: love; violence; intimacy; interpretative repertoires; culture

\section{Introdução}

Vários estudos culturais (e.g., Jackson, 2001; Towns \& Adams, 2000; Vandello, Cohen, Grandon, \& Franiuk, 2009) têm indicado a ligação entre os discursos e as significações sobre o amor e as práticas relacionais abusivas no contexto da intimidade. Maioritariamente, têm-se centrado no discurso das mulheres vítimas (e.g., Wood, 2001) e dos homens agressores (e.g., Borochowitz, 2008), não havendo estudos que procedam à sua contrastação com mulheres e homens sem história de violência. Focando especificamente os jovens, dada a especificidade da fase desenvolvimental da adolescência/juventude, os estudos desenvolvidos com as vítimas e com os agressores jovens não procedem a uma análise comparativa com as vítimas adultas e os agressores adultos.

Assim, consideramos que a investigação cultural sobre a violência e o amor não deve limitar-se à análise dos discursos dos sujeitos com histórias de violência, tornando-se fundamental considerar também os discursos dos sujeitos sem histórias relacionais violentas. Importa perceber se os discursos veiculados pelas vítimas e pelos agressores que sustentam a violência se circunscrevem a estes grupos ou se, pelo contrário, têm continuidade nos sujeitos sem história de violência. Neste sentido, no presente estudo procuramos compreender quais as grelhas disponíveis culturalmente para significar o amor e se existem, ou não, significações específicas que distingam os sujeitos com história de violência dos sujeitos sem história de violência e, mais especificamente, se existem particularidades no discurso dos jovens.

\section{Os estudos culturais sobre o amor e a violência}

O amor e a violência na intimidade têm sido analisados, maioritariamente, de forma separada, como fenómenos distintos ou não se considerando 
a sua interligação (Dias \& Machado, 2011). No entanto, o desenvolvimento recente dos estudos culturais (e.g., Hatfield \& Rapson, 2005) e narrativos (e.g., Fraser, 2003; Maxwell, 2007), inspirados pelo construcionismo social, conduziu ao reconhecimento da dimensão cultural dos fenómenos e da sua interligação. Vários estudos procuram identificar os discursos culturais dominantes sobre o amor veiculados pela cultura nos media e nas narrativas populares (e.g., Carpenter, 1998; Wilding, 2003), analisam os discursos e significados sobre o amor e a violência em contextos culturais/etnias específicos (e.g., Perilla, 1999; Puente \& Cohen, 2003) ou em populações especiais, como as vítimas e os agressores (e.g., Borochowitz, 2008; Wood, 2001) ou, ainda, os jovens (e.g., Jackson, 2001; Wood, Maforah, \& Jewkes, 1998).

No âmbito dos estudos culturais, Hatfield e Rapson (2005), numa vasta revisão dos estudos que analisam o amor e algumas das suas expressões mais intensas e/ou violentas (tais como, o ciúme, a rejeição, o amor não correspondido e alguns tipos de violência), concluem que há diferenças culturais na interpretação, intensidade e expressão das experiências emocionais amorosas e que é a cultura que determina o que é, ou não é, perturbador numa relação, o que desencadeia reações negativas mais intensas, bem como modela a adoção de práticas relacionais abusivas ou violentas.

Outros autores referem que, em muitas culturas, a violência é percepcionada como uma manifestação ou prova de afeto (e.g., Puente \& Cohen, 2003) e indicam que há determinadas "idealizações" sobre o amor que reforçam a perpetração e desvalorização dos maus-tratos, tanto pelas vítimas como pelos agressores (Jackson, 2001; Romkens \& Mastenbroek, 1998; Wood et al., 1998).

Vários estudos, desenvolvidos em culturas específicas, procuram explorar a relação entre a violência e os significados, as normas e os valores associados ao amor e às relações de intimidade, nomeadamente, a fidelidade e a lealdade (e.g., Puente \& Cohen, 2003; Vandello et al., 2009; Vandello \& Cohen, 2003). Por exemplo, Puente e Cohen (2003) referem que o ciúme extremo e a violência são considerados manifestação de amor nas culturas de "honra", como na cultura brasileira, mas que, também na cultura americana, a violência masculina, quando enquadrada pelo ciúme, é interpretada como um sinal de amor.

Na cultura chinesa, Tang, Wong e Cheung (2002) identificaram, também, scripts sociais sobre o amor que legitimam a violência conjugal. Num estudo com focus-groups, concluíram que a vitimação é dissipada pelo script social do amor, no qual as mulheres batidas não são percepcionadas como vítimas mas como mulheres que são amadas e educadas pelos seus maridos. Indicam que este script justifica e romantiza os atos de violência, considerando que, por amor, os homens disciplinam as mulheres e que, também por amor, as mulheres tendem a aceitar os maus-tratos. 
Além dos estudos culturais, os estudos centrados nas narrativas têm salientado a dimensão construída e cultural da interligação do amor e da violência, indicando que há significações sobre o amor que influenciam a perpetração da violência e que contribuem para a tolerância, a legitimação e a manutenção de relações abusivas (Fraser, 2003, 2005; Jackson, 2001; Towns \& Adams, 2000; Wood, 2001). Referem que a cultura proporciona narrativas românticas (através das histórias infantis, da música, das séries televisivas, dos filmes e das revistas) que veiculam normas, valores, expectativas e guiões de comportamento que constrangem o modo como as pessoas fazem sentido das relações e como se posicionam nas relações de intimidade (Fraser, 2003, 2005; Jackson, 2001). A maioria destes estudos indica que se trata de narrativas culturais genderizadas (Fraser, 2005), que reforçam a fusão entre amor e violência (Jackson, 2001) e que veiculam relações de poder (Towns \& Adams, 2000).

Wood (2001), por exemplo, num estudo com mulheres vítimas de violência, identificou duas narrativas românticas: a narrativa do conto de fadas, do príncipe encantado que corteja a princesa, em que a relação é descrita de forma idealizada e os atos abusivos são desvalorizados; e a narrativa do romance negro, em que a relação de amor é descrita como tipicamente dolorosa para a mulher, sendo expectável que o homem seja controlador e, até, violento. Conclui que são narrativas culturalmente enraizadas, que conceptualizam as relações violentas como toleráveis ou, mesmo, preferíveis a não ter qualquer relação. Num estudo com agressores, Borochowitz (2008) identificou a presença da noção do amor fusão, através da qual os homens incorporam a mulher na sua identidade e anulam a individualidade da parceira, surgindo a violência como estratégia de a "moldar" ou "disciplinar", na tentativa de alcançar o guião relacional que idealizaram.

No que diz respeito aos jovens, só a partir da década de 80, com o estudo de Makepeace (1981), o fenómeno da violência no namoro começou a ser alvo de atenção por parte da comunidade científica, ao nível internacional (e.g., Pirog-Good \& Stets, 1989) e, mais recentemente, ao nível nacional (e.g., Caridade \& Machado, 2006; Caridade, 2011), revelando a ampla disseminação da violência nas relações de intimidade juvenis. Assim, apesar dos estudos sobre a prevalência do fenómeno e sobre as atitudes dos jovens face à violência (cf., Caridade, 2011), a sua conexão aos discursos sobre o amor só muito recentemente tem começado a ser foco de análise.

Jackson (2001), por exemplo, indica que as raparigas adolescentes, na fase da construção da sua identidade, são particularmente vulneráveis às narrativas culturais românticas e que estas narrativas prescrevem a dependência e submissão feminina, veiculam guiões genderizados e reforçam a fusão entre o amor e a violência. Num estudo com adolescentes vítimas de violência no namoro, concluiu que as jovens recorriam a narrativas românti- 
cas para contar a sua história (a expectativa do "conto de fadas", a idealização do "príncipe" que as salva e que, simultaneamente, precisa ser amado por elas), ditando a submissão das jovens à relação e a sua tolerância a comportamentos abusivos. Por sua vez, Romkens e Mastenbroek (1998), num estudo com adolescentes alemãs, referem que há construções socioculturais sobre o amor que as torna vulneráveis à violência: o ciúme e o controlo como sinal de amor, a extrema idealização do parceiro e da relação, bem como a entrega e a pertença ao parceiro.

No âmbito das relações de intimidade juvenis, a literatura indica a adolescência como uma fase desenvolvimental decisiva, sendo o período em que se estabelecem as primeiras interações e práticas amorosas e se desenvolvem atitudes, valores e significações sobre a intimidade e as relações amorosas (Caridade, 2011; Matos, Machado, Caridade, \& Silva, 2006; Wekerle \& Wolfe, 1999). Os estudos indicam que os jovens, pelo período desenvolvimental em que se encontram, podem formar e consolidar significados e construções "míticas" sobre o amor e sobre as relações afetivas, tais como a associação do ciúme ao amor, a violência como manifestação de amor, a indissolubilidade das relações (Black \& Weiz, 2003), que promovem e sustentam a tolerância e a legitimação de práticas relacionais abusivas, confundindo violência e amor (Caridade, 2011; Caridade \& Machado, 2006).

Da análise dos estudos, consideramos que o fenómeno da violência, tanto nas relações adultas como nas relações juvenis, não pode ser analisado sem se considerar os discursos sobre o amor e a intimidade. Adotando uma perspetiva construcionista social, conceptualizamos o fenómeno do amor como sendo socialmente construído através dos discursos e práticas dos sujeitos em interação (Jackson, 2001; Towns \& Adams, 2000; Wetherell, 1995, 1998), discursos estes que constrangem a forma como os sujeitos vivenciam as relações de intimidade e, logo, o seu envolvimento em relações disfuncionais e abusivas ou, pelo contrário, em relações mais funcionais e não abusivas. Assim, entendemos que é necessário compreender como os discursos socioculturais sobre o amor podem ser usados e transformados, tanto para facilitar ou sustentar a violência na intimidade, como para limitar ou inibir o seu uso.

Neste âmbito, apesar do vasto leque de estudos que indicam que os sujeitos em relações abusivas (vítimas e agressores) apresentam discursos e significações sobre o amor que legitimam e sustentam a violência na intimidade, analisando-os em profundidade, não encontramos estudos que procedam à análise comparativa com o discurso dos sujeitos em relações não abusivas. O mesmo se verifica nos estudos desenvolvidos com jovens, não havendo uma análise comparativa entre o discurso dos jovens com historial de violência e o discurso dos jovens sem este historial. Além disso, mesmo os estudos desenvolvidos com vítimas ou com agressores jovens, dada a especificidade desta fase desenvolvimental, não há estudos que procedam à sua contrastação com vítimas adultas e agressores adultos. 
$\mathrm{Na}$ nossa opinião, consideramos que a investigação cultural sobre a violência e o amor não deve limitar-se à análise dos discursos dos sujeitos com histórias de violência. Além da identificação e análise dos discursos que facilitam e sustentam a violência na intimidade, é necessário analisar, também, os discursos que a podem limitar e que promovam relações mais funcionais. Neste sentido, torna-se indispensável, a par com as vítimas e agressores, dar voz a homens e a mulheres sem histórias relacionais violentas, procedendo à sua contrastação.

Assim, no presente artigo, pretendemos colmatar algumas destas lacunas. Adotando uma perspetiva sociocultural, procuramos identificar as grelhas culturais disponíveis para significar o amor e as relações de intimidade e proceder à análise comparativa da sua utilização pelos sujeitos com historial de violência e pelos sujeitos sem historial de violência, quer da população juvenil quer da população adulta. O objetivo central é compreender de que forma os discursos sobre o amor pode facilitar ou, pelo contrário, limitar, o estabelecimento e a vivência de relações de intimidade violentas.

Mais detalhadamente, orientamos a nossa análise pelas seguintes questões:

- Quais os discursos sobre o amor e a intimidade veiculados pelos sujeitos com história de violência e pelos sujeitos sem história de violência? Como se caracterizam? Há diferenças? Há aspectos consensuais?

- Focando mais especificamente os jovens, há diferenças entre o discurso dos jovens com história de violência e o dos jovens sem história de violência? Há aspetos consensuais?

- Focando mais especificamente os sujeitos com história de violência, há diferenças entre o discurso dos jovens e o dos adultos? Há aspetos consensuais?

\section{Método}

\section{Participantes}

Participaram no estudo 24 participantes com história de violência nas relações de intimidade - relatada pelos próprios ou sinalizada pelo sistema judicial - e 28 participantes sem historial de violência. Incluímos jovens, com idades compreendidas entre os 15 e os 25 anos, e adultos de diferentes faixas etárias (dos 26 aos 62 anos).

Dos 24 participantes com história de violência, 12 são agressores do sexo masculino ( 9 adultos e 3 jovens) e 12 são vítimas do sexo feminino ( 9 adultos e 3 jovens). Para conseguirmos histórias de vitimação e de perpetração mais salientes e significativas, adotamos como critério a existência de violência física (e não, unicamente, a violência verbal e a violência psicológica). 
Dos 28 participantes sem historial de violência, 14 são mulheres (5 jovens e 9 adultas) e 14 são homens (5 jovens e 9 adultos). Nas mulheres adultas e nos homens adultos considerámos os diferentes estados civis (casados/as ou união de facto, solteiros/as e divorciados/as ou separados/as) e nas mulheres e nos homens jovens a situação relacional (numa relação de namoro, saídos de uma relação de namoro, sem histórico de relação).

\section{Material e Instrumentos}

Utilizou-se a entrevista semiestruturada "A história de amor da sua vida" (Machado \& Dias, 2007), adaptada do guião da entrevista The Life Story Interview, de McAdams (1995). O instrumento foi administrado individualmente, pedindo-se a cada participante que identificasse e descrevesse de forma detalhada a história de amor da sua vida. O guião foca os seguintes tópicos: resumo da história, capítulos da história, momentos importantes (e.g., momento alto, momento baixo, ponto de viragem), desafios, futuro (o melhor futuro possível, o pior futuro possível) e ideologia pessoal (valores e crenças pessoais). Apesar desta estrutura prévia, as questões foram formuladas de forma a permitir que a narrativa fluísse de acordo com os interesses dos participantes, pelo que a ordem e organização variam de entrevista para entrevista mas todos os tópicos do guião foram abordados.

\section{Procedimentos}

Para aceder aos participantes sem história de violência, fez-se uso de contactos informais e da técnica snowballing, a par da divulgação do estudo na zona Norte e Centro do País em Juntas de Freguesia e em Associações. Os participantes com história de violência foram, na sua maioria, encaminhados pelo Serviço de Consulta da Universidade do Minho (agressores e vítimas, cujas perícias foram conclusivas quanto à situação de violência), havendo apenas 3 vítimas e três agressores que foram identificados na recolha dos participantes sem história de violência (violência relatada pelos próprios).

As entrevistas foram realizadas nas instalações disponibilizadas pelas instituições que encaminharam voluntários/as para o estudo e nas instalações do Serviço de Consulta da Escola de Psicologia da Universidade do Minho. Foi utilizado um formulário com o consentimento informado, dando a conhecer os objectivos do estudo e todos os procedimentos seguintes (gravação, transcrição, análise e divulgação dos resultados), garantindo o anonimato dos participantes. Todas as entrevistas foram conduzidas pela investigadora responsável pelo estudo, variando o tempo de duração entre os quarenta e cinco minutos e as duas horas e meia. As entrevistas foram gravadas e transcritas na totalidade, no sentido de preservar a integridade dos relatos. 


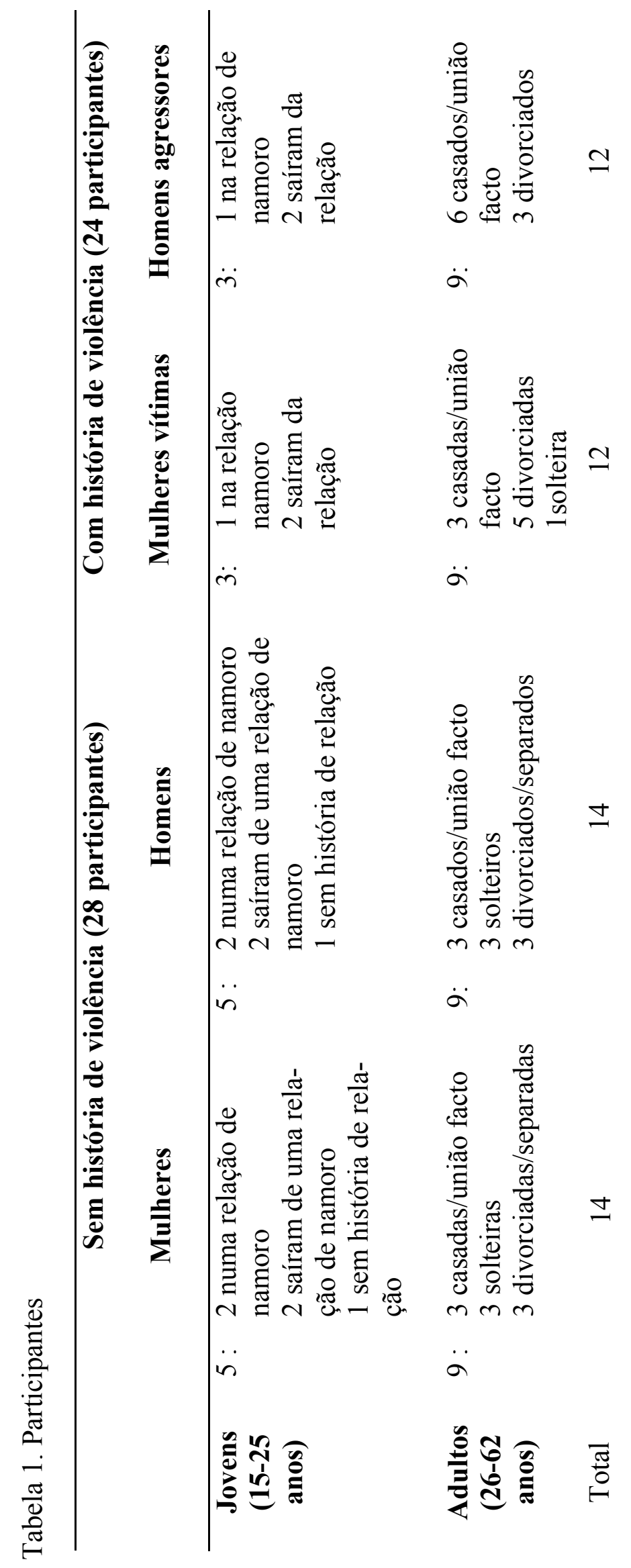




\section{Estratégia analítica}

Utilizou-se a metodologia da análise do discurso, sendo a metodologia qualitativa mais congruente com a perspectiva construcionista social (Wiggins \& Riley, 2011), permitindo-nos compreender como os fenómenos são construídos e reproduzidos através da linguagem (idem). A análise do discurso foi seguida tal como indicada por Wiggins e Riley, utilizando-se o repertório interpretativo como conceito metodológico (Wheterell \& Potter, 1988). Recorremos ao software NVivo 9.0 (QSR, 2010) para o processo de organização, codificação e análise dos dados.

Todas as entrevistas foram codificadas individualmente, codificando-se todo o material. A codificação seguiu um processo interativo e itinerante, de interpretação e recodificação dos dados, havendo um processo cíclico entre a codificação e a análise dos dados - após a primeira codificação foi necessário voltar ao dados, recodificar e rever todas as entrevistas, sendo um processo complexo (Wiggins \& Riley, 2011).

$\mathrm{O}$ argumento (isto é, o conjunto de ideias, significados ou imagens que os participantes pretendem apresentar através das palavras num determinado extrato) foi usado como unidade de análise, não se limitando à frase ou ao parágrafo. Na codificação fomos o mais inclusivos possível, no sentido de evitar ocultar qualquer extrato potencialmente importante na categoria definida. As categorias não são mutuamente exclusivas, podendo codificar-se o mesmo extrato em várias categorias. Focando especificamente todo o conteúdo relacionado com "Amor e relações amorosas", procedemos às seguintes etapas (Wiggins \& Riley, 2011):

(i) Em primeiro lugar, categorizámos as ideias centrais dos relatos e os significados associados, criando notas sobre os termos, palavras, ideias ou imagens mais salientes utilizados para que os participantes construíssem determinados argumentos. Isto ajudou a fase posterior, possibilitando a identificação de padrões.

(ii) Concluída a primeira fase, procurámos regularidades e padrões no discurso dos participantes quando falam sobre amor e as suas experiências amorosas, recorrendo, então, às ideias, termos, significados e imagens mais salientes da fase anterior. Aqui começaram a notar-se similaridades e, muitas vezes, sobreposições, começando a surgir categorias mais amplas. Nesta etapa, numa primeira fase, o número de categorias era elevado, pelo que foi necessário voltar à leitura dos dados codificados em cada categoria, bem como reajustar, recodificar e condensar as categorias mais amplas, focando os principais padrões transversais no discurso: identificar o que surge "junto", a interligação de ideias, termos e significados, as sobreposições, as redundâncias. As etapas 1 e 2 foram, ciclicamente, repetidas, de forma a passar do plano descritivo dos relatos para o plano conceptual dos repertórios. 
(iii) Numa terceira etapa, alcançado um primeiro "esboço" dos repertórios, voltámos novamente aos dados, de forma verificar todos os extratos que constituem os repertórios, bem como as subcategorias que os integram, havendo reajustes e, até, recodificações.

(iv) Por fim, seguiu-se a etapa de identificação dos repertórios, em que classificámos todos os extratos que melhor representam as diferentes formas de falar sobre o amor e as experiências amorosas (repertórios), isto é, os que compartilham um modo particular de falar sobre o tema. Este processo foi repetido várias vezes, ciclicamente, até se encontrar um modo congruente de, conceptualmente, integrar as diferentes formas de falar sobre o amor e as relações.

Por fim, há que referir que, recorrendo ao Nvivo 9.0 (através da funcionalidade das matrizes que permite contabilizar os relatos/quantidade de texto codificados nas categorias, considerando os atributos dos sujeitos) contabilizámos a percentagem dos relatos (quantidade de texto) que constitui cada repertório em cada grupo analisado (e.g. grupo "com história de violência", grupo "sem história de violência").

\section{Resultados}

Para facilitar a leitura, apresentamos os resultados seguindo as questões, já referidas, que orientaram a nossa análise.

Quais os discursos sobre o amor e a intimidade veiculados pelos sujeitos com história de violência e pelos sujeitos sem história de violência?

Tabela 2 - Comparação percentual dos repertórios utilizados pelos participantes sem história de violência e pelos participantes sem história de violência

\begin{tabular}{ccc}
\hline Repertórios & $\begin{array}{c}\text { Com história } \\
\text { de violência }\end{array}$ & $\begin{array}{c}\text { Sem história } \\
\text { de violência }\end{array}$ \\
\hline Amor Companheiro & $29.65 \%$ & $39.27 \%$ \\
Amor Romântico & $39,97 \%$ & $29,47 \%$ \\
Amor Pragmático & $13,02 \%$ & $18,94 \%$ \\
Amor Apaixonado & $16,51 \%$ & $6,99 \%$ \\
Amor Game-Playing & $0,85 \%$ & $5,32 \%$ \\
\hline
\end{tabular}

Valores calculados automaticamente no Nvivo, utilizando as matrizes que contabilizam a percentagem dos relatos codificados em cada repertório, em função dos atributos "com história de violência" e "sem história de violência". 
Identificaram-se cinco repertórios interpretativos sobre o amor: o amor companheiro, o amor romântico, o amor pragmático, o amor apaixonado e o amor game-playing - partilhados tanto pelos sujeitos com história de violência, como pelos sujeitos sem qualquer histórico de violência (sofrida ou perpetrada). Como podemos verificar na análise da tabela 2 , o que os distingue, não é a existência de repertórios específicos ou exclusivos, mas o diferente padrão de utilização e de relevância que os repertórios assumem nos seus discursos.

Os sujeitos com histórico de violência recorrem mais ao repertório amor romântico (39,97\%), seguindo-se o companheiro $(29,65 \%)$ e o apaixonado $(16,51 \%)$, surgindo em quarto lugar o pragmático $(13,02 \%)$ e, por último, escassamente, o game-playing $(0,85 \%)$. Na sua maioria, utilizam o repertório romântico ao longo de toda a sua história: como ponto de partida para a história (guião tradicional, fase cor-de-rosa e idealização da relação), no desenvolvimento da história (prescrição dos valores românticos e das metáfora do "amor vencedor" e do "amor sacrifício" para manter a relação), incluindo a conceptualização dos problemas e a frustração dos ideais românticos (sub-repertório desencantado), bem como, até, como projeção no futuro (expectativa do "final feliz"). Alternam com o repertório amor companheiro para reforçarem a permanência/recuperação da relação, recorrendo às noções do entendimento, aceitação e diálogo, que sustentam a crença na mudança do parceiro/a e da relação. O repertório amor apaixonado assume, também, maior relevância no grupo com história de violência, principalmente a noção da alteração do seu estado normal pela intensidade do amor, servindo para justificar comportamentos abusivos.

Por seu turno, nos sujeitos sem histórico de violência, o repertório amor companheiro $(39,27 \%)$ é o mais utilizado, seguindo-se o romântico $(29,47 \%)$ e o pragmático $(18,94 \%)$ e, muito pontualmente, o apaixonado $(6,99 \%)$ e o game-playing $(5,32 \%)$. Utilizam, maioritariamente, o repertório amor companheiro como prescrição para manter/gerir a relação, recorrendo apenas ao amor romântico como ponto de partida e como projeção no futuro (em termos de expectativa e não como prescrição). Significativo é o facto de usarem, bastante mais, o amor pragmático, em detrimento do apaixonado, veiculando um discurso mais ponderado e cauteloso, nomeadamente, a listagem de atributos desejáveis para a escolha do parceiro e a análise das condições para o estabelecimento/consolidação da relação - inclusive na fase inicial da relação e não só no final (após a vivência de más experiências), como sucede com os sujeitos com histórico de violência.

Por fim, apesar do repertório game-playing ser pouco utilizado por ambos os grupos, assume maior relevo nos sujeitos sem histórico de violência, dado que é quase inexistente no discurso dos sujeitos com histórico de violência, que o usam como antítese do "verdadeiro" amor, inscrito no reper- 
tório romântico. Isto, no nosso entender, prende-se com a maior vinculação dos sujeitos com história de violência aos ideais do repertório amor romântico, que sustenta formas relacionais mais convencionais e de comprometimento, o que resulta na maior dificuldade em adotar conceptualizações do amor mais abertas e formas relacionais alternativas.

Procedendo, seguidamente, à análise específica e detalhada de cada um dos repertórios, verifica-se que, além dos diferentes padrões de utilização e relevância dos repertórios, a amplitude dos significados que constitui cada um dos repertórios difere entre os dois grupos.

\section{Repertório amor companheiro}

É partilhado por ambos os grupos e assenta na associação entre o amor e a amizade/companheirismo, no conhecimento mútuo, na noção da necessidade de adequação dos parceiros, de ajuda, de compreensão e do entendimento entre ambos, bem como na importância da comunicação e do diálogo. A sinceridade, a confiança, a honestidade surgem como valores importantes e essenciais neste repertório, em que a fidelidade e o respeito são hipervalorizados por ambos os grupos.

No âmbito deste repertório, os sujeitos sem historial de violência apresentam um maior leque de significações, integrando noções que não estão presentes nos sujeitos com histórico de violência, nomeadamente: o conceito de cumplicidade ("A cumplicidade é essencial. Sermos cúmplices em tudo, um do outro.") e, principalmente, a noção da partilha comum de experiên-

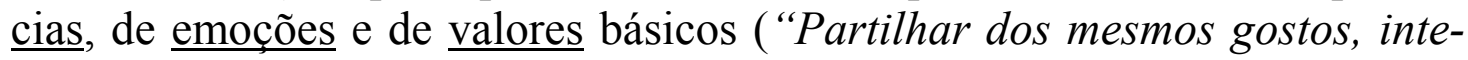
resses e fazermos muitas coisas juntos. Principalmente, defendermos os mesmos valores.").

Neste repertório, o tema da infidelidade é muito focado por ambos os grupos, sendo conceptualizada como uma violação dos valores e expectativas do repertório amor companheiro (honestidade, respeito, sinceridade) e, logo, usada como motivo para a emergência de conflitos. Neste âmbito, a linha que separa os sujeitos com conjugalidade violenta dos sujeitos sem história de violência é muito ténue, dado que a infidelidade é conceptualizada como uma "ferida" na relação. O que se verifica nos sujeitos com histórico de violência, principalmente nos agressores, é a sua conotação negativa mais extremada e a dificuldade em aceitar e superar, sendo vista como irremediável por colocar em causa a sua autoimagem e a masculinidade. Assim, nos agressores, a construção da infidelidade como violação "irreparável" dos valores "companheiros", associada à percepção da ausência dos ingredientes essenciais que defendem neste repertório (compreensão, acordo, entendimento, comunicação), são usadas como argumentos para a perpetração de violência sobre a parceira. 
Sem história de violência, 28 anos, homem solteiro: "Ser traído... é o pior que pode acontecer. É uma ferida que fica para sempre. Já não se pode apagar."

Agressor, casado, 43 anos: "Uma mulher tem de ser fiel, honesta. Se não... já não há nada a fazer, é uma mancha que fica para sempre... ou é honesta ou não é. E se não é... um homem tem de defender a sua dignidade, não é?!"

Agressor, casado, 52 anos: "Fui mal compreendido e ela não me ajudava. Uma mulher deve entender, estar de acordo com o marido mas ela não... e eu era mais agressivo porque ela não entendia."

Por outro lado, no caso das vítimas, os mesmos significados (compreensão, acordo, entendimento, comunicação, ajuda mútua) sustentam a crença na mudança do parceiro e da relação, sendo usados para justificar a sua permanência na relação e a tolerância à violência.

Vítima, 52 anos, casada: "Vou dar-lhe mais uma oportunidade. A falar é que as pessoas se entendem e chegam a um acordo. Se houver ajuda e compreensão entre nós, os problemas podem resolver-se."

\section{Repertório amor romântico}

O repertório romântico é usado, quase sempre, por todos os participantes, como o ponto de partida das histórias que nos relatam, onde descrevem o guião tradicional das relações: a associação do amor a uma relação de compromisso e duradoira, preferencialmente que culmine no casamento e que seja para sempre, havendo uma idealização da relação e do parceiro (fase cor-de-rosa) e a expectativa de um final feliz. Tanto os sujeitos com história de violência como os sujeitos sem história de violência partilham as noções do amor verdadeiro, da pessoa certa e da necessidade de ter uma relação de amor para alcançar a felicidade. Este repertório inclui ainda a metáfora do amor vencedor, partilhado por ambos os grupos, no qual está patente a crença de que o amor vencerá todos os obstáculos e dificuldades.

Sem história de violência, 28 anos, mulher solteira: "Com amor tudo se supera."

Vítima, 30 anos, solteira: "O amor é a base de tudo e pensamos que havendo amor podemos vencer tudo. Se houver, vencemos os obstáculos e os problemas."

Além da partilha comum destes significados, os sujeitos sem histórico de violência integram ainda outros, ampliando o leque de significações, comparativamente aos sujeitos com história de violência, nomeadamente: na noção de "verdadeiro amor", consideram as anteriores relações como "tentativas de ensaio e erro" ("Houve outras relações, outras histórias, mas não... 
foram experiências, tentativas, até ter encontrado o $\mathrm{H}$. Com ele foi completamente diferente, é um amor verdadeiro. "); a conceptualização do parceiro como complemento e fonte de equilíbrio ("Completamo-nos. Somos o complemento e o equilíbrio um do outro."); a valorização do "romantismo" e do sentimento "amor" ("É importante manter o romantismo, basta uma palavra, um elogio, um olhar"; "Amar é a coisa mais bonita do mundo, o melhor que nos pode acontecer."); e a metáfora "efeito cupido", no sentido de, quando ou com quem menos se espera, o amor surge naturalmente e é capaz de esbater as diferenças ("O amor surgiu ali, entre dois seres completamente diferentes e que jamais se olhariam.")

Por outro lado, verifica-se que os sujeitos com história de violência, além do menor leque de significados, os significados assumem um caráter mais extremado e rígido, adotando posicionamentos menos flexíveis que fecham/limitam as possibilidades de ação no âmbito relacional: na expectativa do "final feliz" sustentam a crença romântica de que "o amor basta" para resolver os problemas e a relação ser bem-sucedida, bem como alicerçam mais as noções da indissolubilidade da relação e do imperativo que a relação e a pessoa amada se sobreponham a todas as prioridades individuais (para que o amor "vença").

Vítima, 40 anos, divorciada: "Pensamos que o amor é suficiente para resolver qualquer problema. Que basta o amor."

Agressor, 33 anos, divorciado: "Acredito que ainda podemos ser felizes, o amor quando é amor é para sempre."

Além disto, tanto as vítimas como os agressores, apesar do leque mais restrito de significados, apresentam duas especificidades no seu discurso que não estão presentes nos participantes sem história de violência:

(i) a metáfora do "amor sacrifício", nomeadamente a noção de abdicar e ceder por amor, fazendo sacrifícios pessoais em prol da relação - que, nas vítimas, é usada para sustentar a sua permanência na relação violenta e a tolerância aos maus-tratos (Vítima, 30 anos, união de facto - "vamos suportando porque no casamento temos de ceder, o amor também é sacrificio") e, nos agressores, é usada para reforçar o seu investimento na relação e fundamentar a imagem de "ingratidão" da parceira (Agressor, 43 anos, casado: "Fartei-me de trabalhar, fui para o estrangeiro. Tudo por ela e pela minha filha... e ela desprezou-me. Nem me atendia o telemóvel.. e qualquer homem agia como eu!'”)

e (ii) a construção discursiva do amor desencantado que constitui um sub-repertório do amor romântico, sob o qual descrevem o desencanto/desilusão dos ideais e sonhos românticos e fundamentam a noção do sofrimento e mal-estar psicológico face à frustração dos sonhos românticos e 
a descrença no amor e nas relações. Recorrendo à imagem do desencanto/desilusão dos sonhos românticos, principalmente com base no confronto com os problemas do quotidiano (problemas financeiros, problema aditivos, fatores externos de stress), tanto os agressores como as vítimas justificam a emergência de conflitos.

\section{Repertório amor apaixonado}

No repertório amor apaixonado, ambos apresentam a noção de que o amor constitui uma alteração do seu estado normal (em termos cognitivos, emocionais e físicos), assente na intensidade afetiva e que pode levar a comportamentos ou atitudes que escapam ao seu controlo. Neste âmbito, enquanto os sujeitos sem história de violência se limitam à incontrolabilidade emocional, os sujeitos com histórico de violência generalizam à componente comportamental, associando os comportamentos de violência à intensidade emocional e, até, irracional, do amor. Isto sucede tanto nas vítimas como nos agressores, havendo uma desresponsabilização do agressor em nome da incontrolabilidade do amor que, por um lado, sustenta a tolerância aos maus-tratos por parte das vítimas e, por outro, sustenta a legitimação da violência por parte dos agressores.

Agressor, 31 anos, união de facto: "O amor era muito intenso. $E$ quando as emoções são, assim, tão intensas, tu não consegues controlar e chegas a ser fisicamente agressivo. Perdi o controlo e bati-lhe."

Vítima, 20 anos, relação de namoro: "É um bocado agressivo... violento. Mas eu sei que ele me ama, é a forma dele mostrar que me quer".

\section{Repertório amor pragmático}

O repertório amor pragmático é, também, partilhado por ambos os grupos, ainda que menos frequente no discurso dos sujeitos com história de violência, que o usam exclusivamente no final das narrativas. Neste repertório, conceptualizam o amor sob uma perspetiva mais prática e calculada, sendo utilizado para contrabalançar significações mais "idealistas" e proceder a uma reflexão ponderada das experiências relacionais. A ideia de aprendizagem/amadurecimento, após o balanço das experiências relacionais, é amplamente partilhada, bem como a listagem de vantagens/desvantagens da relação e a listagem dos atributos desejáveis do parceiro, que acarretem ganhos para o próprio. Além disto, inclui uma visão mais flexível das relações, como a noção da vulnerabilidade do amor às contingências da vida.

Um aspeto diferenciador no âmbito deste repertório é que os sujeitos sem história de violência usam-no ao longo da sua história, em que referem a análise ponderada das condições pessoais e materiais de ambos os parceiros 
para avançarem e investirem na relação, ao contrário dos sujeitos com história de violência, que o usam exclusivamente no final para proceder ao balanço do que falhou na relação.

Sem história de violência, 28 anos, casada: "Aquela fase de apalpar um bocadinho o terreno e perceber se, de facto, é aquela pessoa. Depois analisar as condiçoes para um projeto de vida, de toda aquela fase que se prolongou durante bastante tempo, de termos condições para o fazer"

Sem história de violência, 42 anos, solteira: "Perceber «isto é muito forte, muito intenso, mas o mal que provoca é superior ao bem que alguma vez na vida tirarei daquilo», até, de facto, se tomar a decisão de interromper este relacionamento porque estava a tornar-se complicado de gerir."

Vítima, 40 anos, divorciada: "Percebi muito tarde que ele não ia mudar. Ele só me fazia mal, muito mal. Era mais o sofrimento do que outra coisa qualquer. Coisas boas... olha, nenhuma! Agora sou eu que estou em primeiro lugar. Deixei de ser burra."

No caso dos agressores, é usado exclusivamente para dar sentido à rutura, emergindo apenas nos que foram deixados pelas companheiras: a rutura da relação é avaliada como sendo a melhor opção e há um foco nos benefícios que trouxe para o próprio. Esta estratégia da ponderação dos ganhos permite-lhes aceitar a rutura e manterem-se emocionalmente distanciados. Também nas vítimas é usado para conceptualizar a saída ou equacionar essa possibilidade, sendo o repertório que permite desconstruir a crença na mudança do parceiro e/ou da relação e a tomar a decisão (ou equaciona a possibilidade) de sair da relação.

Agressor, 46 anos, divorciado: "Olhe, o melhor momento que tive na vida é agora! Sinto-me livre! Era só "discutimentos"! Agora é um sossego."

Vítima, 45 anos, união de facto: "O melhor futuro possivel era eu separar-me dele, completamente. E ficar sozinha com os meus filhos... Eu só quero sair e seguir com a minha vida. Aquele homem nunca vai mudar e eu também já não quero." 


\section{Repertório amor game-playing}

É o repertório menos recorrente no discurso dos dois grupos (embora, menos ainda, no discurso dos sujeitos com história de violência), associado essencialmente à agência masculina, em que as relações são concebidas como um jogo, envolvendo menor investimento emocional, intimidade e compromisso. Esta forma relacional é conceptualizada por todos os participantes como "não amor", sendo associado essencialmente às conquistas sexuais, a relações fugazes e passageiras, à noção de aproveitar o momento e adiar o compromisso. É de notar que, embora muito escasso nos sujeitos com história de violência, é mais usado pelos agressores do que pelas vítimas e, exclusivamente, utilizado como contraponto do "verdadeiro" amor, no sentido de reforçarem o seu amor pela parceira como sendo o "verdadeiro"

Agressor, 43 anos, casado: "Tive várias relações, mas só de um dia ou dois, para passar tempo. Mas sem importância, sem compromisso. E elas sabiam, não pedi nenhuma. Esta é que me agarrou, com ela foi diferente e pedi-a."

Focando mais especificamente os jovens, há diferenças entre o discurso dos jovens com história de violência e o dos jovens sem história de violência?

Os jovens com história de violência e os jovens sem história de violência partilham do mesmo padrão de utilização e relevância dos repertórios mas, no entanto, os jovens sem história de violência usam de forma mais flexível e distribuída os diferentes repertórios. Isto é notório, por exemplo, no repertório game-playing que, sendo o menos utilizado por ambos os grupos, está mais presente nos jovens sem história de violência $(9,53 \%)$ do que nos jovens com história de violência $(1,33 \%)$.

Por outro lado, no que diz respeito às especificidades dos repertórios, verifica-se que os jovens com história de violência se diferenciam, não pela amplitude e especificidade de significados (ambos revelam um leque de significados mais restrito e partilham as mesmas significações), mas pela sua maior vinculação aos significados que mais concorrem para a rigidez, inflexibilidade e intransigência na vivência das relações amorosas: os ideais românticos da exclusividade/prioridade da relação, da fidelidade, do amor verdadeiro, do amor união/fusão; as construções "apaixonadas" do ciúme e da violência como prova de amar de mais, do amor cego e irracional.

Por outro lado ainda, é de referir que os jovens com história de violência tendem a recorrer mais aos significados que promovem uma atitude passiva e, até disfuncional, na resolução dos problemas relacionais, tais como: a noção de que o "o amor basta" para manter a relação, a expectativa que, principalmente a rapariga, abdique e ceda por amor, e a noção do amor 
"transformador" que sustenta a crença na mudança sem a adoção de estratégias ativas de mudança.

Por seu lado, os jovens sem história de violência também fazem uso destes significados mas de forma menos rígida e menos dominante. Há que referir, no entanto, que a intolerância à frustração dos ideais românticos e a ênfase na incontrolabilidade das atitudes e ações pela intensidade do amor é similar. O que distingue os jovens sem histórico de violência dos jovens com historial de violência é o facto de não descreverem situações limite que os tenha levado à adoção de comportamentos violentos. No entanto, verificamos que, quando estes jovens perspetivam essa hipótese (como a infidelidade), não descartam a possibilidade de ocorrer violência.

Sem violência, rapaz, 19 anos, sem relação: "O pior era descobrir que era traído. Nem sei o que faria... nem consigo imaginar. Compreendo que alguns se passem... eu também me passava" (sem violência, 19 anos, sem relação)

Agressor, 16 anos, saiu da relação de namoro: "Saber que ela andava com todos... e quando a encontrei a falar com o rapaz que andava atrás dela, passei-me. Dei-lhe um empurrão e disse-lhe que não queria uma $P^{* * *}$ "

Focando mais especificamente os sujeitos com história de violência, há diferenças entre o discurso dos jovens e o dos adultos?

Contrastando o discurso dos jovens com o dos adultos com história de violência, verifica-se que os jovens apresentam algumas especificidades que os diferenciam dos adultos.

No âmbito do repertório romântico, como já foi referido, identificou-se o sub-repertório desencantado como específico dos sujeitos com história de violência. No entanto, os jovens constituem a exceção, não estando presente nem nas vítimas, nem nos agressores jovens. Os jovens, provavelmente por se encontrarem na fase do estabelecimento das primeiras interações e práticas amorosas, mantêm-se "imunes" ao desencanto e à desilusão dos sonhos românticos. Contrariamente aos adultos, muito focados na desilusão das expectativas românticas, os jovens estão mais centrados na idealização da relação e na expectativa da vivência de um grande amor e do "final feliz", mantendo a crença no "encantamento" do amor, apesar das más experiências e das situações de violência.

Vítima, 52 anos, casada: "O meu amor morreu. Já não acredito no amor. Tudo o que sonhei não aconteceu. Desilusão..."

Vítima, 20 anos, relação de namoro: "Acredito no amor, que as pessoas podem ser felizes. E o amor é a chave para a felicidade, ter uma vida a dois, filhos..." 
Outro aspeto diferenciador é o facto de os jovens agressores integrarem, no repertório romântico, o tema da violência, aspeto que não se verifica nos agressores adultos. Assim, no nosso entender, enquanto a perpetração da violência nos agressores adultos parece colidir com a imagem idealizada do "herói" romântico, pelo que o tema não é incluído quando recorrem a este repertório, nos jovens a perpetração da violência não é dissonante com os sonhos "românticos" (exclusividade/fidelidade, amor união/fusão): os jovens integram a violência quando confrontados com a violação dos ideais românticos (como as situações de infidelidade), que, por ter quebrado o guião do "conto de fadas", é legitimada e tolerada.

Agressor, 17 anos, saiu da relação de namoro: "Ela estava com outro, eu vi-a. O meu mundo acabou, fiquei de rastos, chocado. Foi difícil vê-la a trair-me... quando eu a amava tanto. Discutimos e, na dor, bati-lhe."

Assim, nos jovens, a associação entre o amor e violência surge essencialmente no repertório amor romântico (quando não são corroboradas as expectativas românticas da exclusividade/prioridade da relação, da fidelidade, do amor união/fusão) e, também, no repertório apaixonado (noção do amor cego/irracional e a forte intensidade emocional). Nos adultos, mais do que no repertório apaixonado (sob o argumento da elevada intensidade emocional) e no repertório romântico (descrição da violência como fonte de desencanto/desilusão, no caso das vítimas), a associação amor/violência está mais patente no repertório companheiro: abordam a falta dos valores companheiros na sua relação para justificar a violência e procedem à sua prescrição para sustentar a manutenção/recuperação da relação.

O repertório amor pragmático, pelos significados que inclui (modelo economicista da relação, ponderação de vantagens e desvantagens, listagem de atributos), é o menos compatível com a violência, sendo essencialmente utilizado para conceptualizar a rutura e considerar o processo de tomada de decisão acerca da permanência versus abandono da relação violenta. Neste âmbito, os jovens distinguem-se pela maior ambiguidade entre o sair e o ficar/recuperar a relação, enquanto os adultos revelam posições mais restritas e rígidas no processo de tomada de decisão e na consideração da rutura.

Por outro lado ainda, de uma forma geral, os jovens com história de violência conseguem revelar maior versatilidade e flexibilidade no uso dos diferentes repertórios, o que indica que ainda não apresentam discursos tão restritos e cristalizados, ao contrário dos adultos, que restringem o seu discurso em torno dos repertórios mais "convencionais" e integram os significados e modelos relacionais mais rígidos e extremados, dificultando exponencialmente a alternância entre os diferentes repertórios e a aceitação de perspetivas alternativas. 


\section{Discussão dos resultados}

Dos resultados descritos, há dois aspetos centrais que consideramos essenciais discutir: (i) de que forma os repertórios interpretativos sobre o amor são usados para facilitar e/ou para limitar o estabelecimento e a vivência de relações de intimidade violentas; e (ii), considerando as particularidades discursivas que distinguem os diferentes grupos de sujeitos, explorar potenciais pontos de intervenção (preventiva e remediativa), diferenciados, principalmente com os jovens.

Repertórios Interpretativos sobre o amor - da facilitação à limitação da violência

Como vimos, todos os participantes recorrem, em maior ou menor grau, aos cinco repertórios, o que indica, por um lado, que se trata de grelhas interpretativas consensuais e culturalmente partilhadas e, por outro lado, que os repertórios, por si só, não determinam o estabelecimento de relações de intimidade violentas ou não violentas, dado que estão presentes tanto nos sujeitos que têm como nos que não têm história de violência. No entanto, identificámos diferenças no padrão de utilização e na amplitude dos repertórios, pelo que consideramos que, não sendo os repertórios, em si, que potenciam ou inibem a violência, há padrões de conjugação e estruturação dos repertórios que podem facilitá-la ou, pelo contrário, inibi-la.

Da análise dos resultados, sugerimos que a conjugação entre o repertório romântico, o companheiro e o apaixonado, em concomitância com a escassez do repertório pragmático, parece ser a que mais facilita a legitimação e a tolerância a práticas relacionais abusivas.

O repertório romântico, quando utilizado ao longo da toda a narrativa (ponto de partida, projeção no futuro e, principalmente, na gestão da relação), limita os sujeitos a formas relacionais convencionais, reforça expectativas românticas "idealizadas", restringe a identificação das dificuldades relacionais e dificulta a adoção de estratégias adaptadas para as gerir/solucionar (pela sustentação da crença de que o "amor basta" e da metáfora do "amor vencedor" e, principalmente, pela persecução do guião tradicional como modelo).

Paralelamente, o repertório companheiro, quando usado essencialmente na fase final da narrativa e centrado na "adulteração" ou na "ausência" dos valores que o repertório prescreve (compreensão, acordo, entendimento, comunicação, honestidade), dificulta paradoxalmente a aplicação desses valores e limita a adoção de estratégias ativas de resolução (na medida em que se centra no que falhou e culpabiliza o/a parceiro/a por não ter ou por adulterar os valores "companheiros", dificultando a corresponsabilização do 
próprio e, consequentemente, a aplicação dos valores que prescreve). Além disto, sendo usado como prescrição, mantém a crença na mudança e sustenta a manutenção/investimento na relação, mesmo que insatisfatória ou violenta.

Em articulação com estes repertórios, o repertório apaixonado, ao acrescentar a componente "passional" do amor à relação (a noção de amar "de mais" e intensamente, a alteração do estado normal) sustenta a exasperação emocional e facilita, exponencialmente, a adoção de práticas relacionais abusivas e violentas, legitimadas e toleradas sob a conotação de "manifestações de amor".

Concomitantemente, a escassez do repertório pragmático, que é o menos conciliável com as relações insatisfatórias e com a violência, aumenta a vulnerabilidade dos sujeitos ao envolvimento e à manutenção de relações violentas ou abusivas. Delegado para o final das narrativas (i.e. após a vivência de más experiências) e inexistente nas fases inicial e de investimento na relação amorosa, não é utilizado para contrabalançar as construções mais idealistas e extremadas dos outros repertórios, pelo que não há uma análise e monitorização das condições dos parceiros e das vantagens/desvantagens de estar na relação, desde o ponto de vista do próprio.

Por seu turno, os resultados apontam que a conjugação, entre o repertório companheiro, o romântico e o pragmático, em concomitância com a menor relevância do repertório apaixonado, parece ser a que mais restringe e dificulta a adoção de práticas relacionais abusivas (logo, a legitimação e tolerância face à violência).

O repertório companheiro, sendo dominante ao longo de toda a narrativa e, principalmente, na fase de desenvolvimento/aprofundamento da relação amorosa, permite o foco na gestão das práticas e das dinâmicas relacionais de ambos os parceiros, nomeadamente quando confrontados com dificuldades. Assim, facilita a adoção, na prática, dos valores inscritos neste repertório (compreensão, diálogo, procura de entendimento, companheirismo, amizade, reciprocidade), diminuindo a probabilidade de conflitualidade, e promove a aplicação de estratégias de resolução mais funcionais, minimizando os focos de conflito e dificultando o recurso a comportamentos abusivos.

Paralelamente, o repertório romântico, usado exclusivamente como ponto de partida e projeção no futuro, permite que, na gestão da relação, os "ideais" românticos não deem lugar ao desencanto quando confrontados com dificuldades, permitindo espaço às estratégias ativas de entendimento e de resolução possibilitadas pelos outros repertórios (companheiro e pragmático), sem cair na frustração extrema das expectativas românticas nem na exasperação emocional do repertório apaixonado.

Um repertório fulcral, nesta conjugação que mais limita a violência, é o pragmático, que, como vimos, pelas suas características, é o menos compatível com a vivência/manutenção de relações insatisfatórias e com situações 
abusivas ou de violência. $\mathrm{O}$ uso deste repertório na fase inicial ou no desenvolvimento da relação amorosa (e não só no final, como balanço das experiências negativas), por implicar uma análise e monitorização das condições e das vantagens/desvantagens da relação, parece permitir a detecção de eventuais problemas, possibilitando a adoção de estratégias de resolução mais "funcionais" ou, havendo aspetos inconciliáveis, possibilitando a tomada de decisão de abandonar a relação. Assim, este repertório assume extrema relevância ao funcionar como balizador da relação amorosa e por não contemplar significados que promovam a legitimação e a tolerância à violência, diminuindo, assim, a vulnerabilidade dos sujeitos a relações abusivas.

Concomitantemente, a escassez do repertório apaixonado parece diminuir a vulnerabilidade dos sujeitos a relações abusivas: ao ser usado apenas como ponto de partida (a par do romântico) para descrever a ativação física e emocional do amor, não é considerado na gestão/desenvolvimento da relação. Assim, quando há o confronto com problemas relacionais, não há espaço para a expressão mais "intensa" e "alterada" do repertório apaixonado, dificultando a adoção e/ou legitimação de comportamentos menos ponderados (entre os quais, os violentos).

Repertórios interpretativos sobre o amor - possibilidades de ação e potenciais pontos de intervenção

Os resultados que descrevemos fornecem-nos pistas importantes para a intervenção, quer remediativa quer preventiva. No âmbito da intervenção remediativa, quer com vítimas como com agressores, consideramos que a significação do amor e das relações amorosas deve constituir um tópico central. Como vimos, o leque mais reduzido de significados, principalmente nos repertórios romântico e companheiro, contribui para a adoção de posições mais rígidas e práticas mais extremadas quando os valores, inscritos naqueles repertórios, são quebrados ou quando surgem problemas relacionais, dando espaço à violência "passional" e incontrolável, inscrita no repertório apaixonado. Assim, a intervenção com as vítimas e com os agressores deve contemplar a desconstrução das significações românticas e companheiras mais "extremadas", bem como a desmistificação da construção "passional" da violência. Só desconstruindo estas noções base, se poderá reconstruir novas grelhas de significados que não sejam conciliáveis com práticas abusivas e violentas no contexto da intimidade e do afeto.

Um repertório fulcral parece ser o pragmático que, pelas suas características, é o menos compatível com as relações insatisfatórias e com situações abusivas. Assim, este repertório deve ser trabalhado, tanto com as vítimas como com os agressores, dado que assume extrema relevância ao funcionar como balizador da relação e por não incluir significados que promo- 
vam a legitimação e tolerância à violência, dificultando a sustentação de práticas abusivas.

Além desta análise global, procedemos a contrastações mais específicas e identificámos diferenças entre os jovens com história de violência e os adultos com história de violência, indicando a necessidade de desenvolver intervenções diferenciadas. Relembramos que os jovens recorrem mais ao repertório romântico e ao apaixonado para conciliar a violência com o amor, enquanto os adultos recorrem preferencialmente ao repertório companheiro.

Assim, os resultados indicam a necessidade de, nos jovens, focar a desconstrução dos "significados românticos" (exclusividade/prioridade da relação, fidelidade, amor união/fusão) e das noções "apaixonadas" do amor (ciúme e violência como prova de amor, incontrolabilidade do amor intenso. Por seu lado, nos adultos, os resultados remetem para a necessidade de desconstruir e clarificar os valores "companheiros", não negligenciando a desmistificação do guião "romântico" como modelo, bem como a desconstrução do "desencanto/desilusão" e do "amor passional" como estratégias discursivas de desresponsabilização/tolerância perante a violência.

No âmbito do repertório pragmático, verificou-se que os jovens revelam maior ambiguidade na opção de sair ou ficar/recuperar a relação, enquanto os adultos têm posições mais fixas. Esta ambiguidade dos jovens pode indicar a maior probabilidade de se manterem ou regressarem à relação violenta, pelo que se torna essencial trabalhar o processo de tomada de decisão e, se for o caso, o processo da rutura.

Por fim, o facto dos jovens com história de violência, quando comparados com os adultos com história de violência, revelarem maior diversidade e flexibilidade no uso dos diferentes repertórios, indica que os jovens, mesmo envolvidos em relações violentas, ainda não apresentam discursos muito rígidos e cristalizados, maximizando o potencial da intervenção. Provavelmente, por se encontrarem na fase da descoberta, exploração, desenvolvimento e aprendizagem no âmbito emocional e relacional (Saavedra, 2011), constitui um público-alvo mais maleável e receptivo à mudança.

Como vimos, também os jovens sem história de violência partilham dos mesmos significados "idealizados" e "passionais" dos jovens com história de violência, bem como da intolerância à frustração dos ideais românticos e da noção da perda do controlo do "amor apaixonado": os jovens sem história de violência, quando perspetivam a possibilidade da frustração dos ideais românticos (como a infidelidade), não descartam a possibilidade de ocorrer violência. Isto aponta para a necessidade de desenvolver ações preventivas junto dos jovens em geral, dado que, como vimos, todos começam por usar as construções mais convencionais, idealizadas e rígidas. Assim, tratando-se de uma fase com grande potencial de experimentação e aprendizagem (Saavedra, 2010), há que proporcionar-lhes oportunidades para co-construírem 
grelhas interpretativas e guiões relacionais que promovam relações funcionais, igualitárias e saudáveis.

\section{Conclusões}

Há uma diversidade de recursos culturalmente disponíveis para dar sentido ao amor e à intimidade e a sua associação à violência é mais complexa do que, habitualmente, a literatura supõe. A literatura na área tem enfatizado o papel do amor romântico e do amor apaixonado para a associação amor/violência (Fraser, 2003, 2005; Jackson, 2001; Wood, 2001). No entanto, o nosso estudo indica que, além do amor romântico e do amor apaixonado, outras grelhas de significação podem facilitar aquela associação (como é o caso do amor companheiro ou, ainda, o caso do amor game-playing que, como vimos, inclui noções que remetem para a objetificação do parceiro e pode ocultar a violência pelo facto das relações passageiras não serem, usualmente, consideradas relações de "intimidade" ou de "amor").

Além disto, verificámos que não são os repertórios em si, considerados isoladamente, que promovem a violência mas a conjugação entre os diferentes repertórios e os momentos em que são usados. Apesar das diferenças no padrão de utilização/conjugação e na amplitude de significados, consideramos pertinente realçar que, tanto os sujeitos com histórico de violência, como os sujeitos sem este historial, partilham as mesmas grelhas interpretativas para significar o amor e as relações de intimidade. Fazendo uma análise holística, verificamos que as grelhas interpretativas são comuns, em que o guião romântico e os valores/prescrições do amor companheiro assumem extrema relevância, e a componente "passional", ainda que mais expressiva nos sujeitos com história de violência, não se dissipa, surgindo pontualmente.

Em nosso entender, as conceptualizações românticas e apaixonadas funcionam como pedras basilares, onde os sujeitos começam por edificar as suas histórias - o que é corroborado pela nossa análise, verificando-se que as idealizações românticas e as reações "apaixonadas" são partilhadas por todos os sujeitos como ponto de partida. Por seu turno, o companheirismo, sob a forma de valores básicos, funciona como elemento de desenvolvimento e manutenção, sem deixar de preservar a estrutura romântica e de, pontualmente, recuperar o "colorido" apaixonado (principalmente em fases de transição da vida relacional, como o divórcio ou uma nova relação).

Assim, concluímos que, apesar das diferenças já descritas, há uma partilha consensual transgeracional (jovens e adultos) e trans-historial (sujeitos com história de violência e sem história de violência na intimidade), principalmente do guião romântico e dos valores "invioláveis" do compa- 
nheirismo, cuja frustração é conceptualizada como fraturante. Assim, concluímos que os discursos sobre o amor que podem facilitar, legitimar e tolerar a violência não estão circunscritos à "anormalidade", aos sujeitos "disfuncionais", aos perpetradores ou aos vitimizados. Pelo contrário, em maior ou menor grau, estão presentes nos discursos de todos os sujeitos, nas histórias comuns do quotidiano e são culturalmente partilhados. Isto implica que nós, enquanto sociedade, temos que reconhecer, e refletir criticamente, sobre o nosso papel na co-construção do fenómeno de "amar violentamente", obrigando-nos a sair da "zona neutra" - de que a violência na intimidade é algo que só diz respeito aos outros e que está nos outros, isto é, nos que agridem e nos que são vitimizados. O "amor violento" faz parte do discurso social e acarreta várias funções dentro dos discursos públicos e privados (como a manutenção da estrutura social convencional, a preservação da família tradicional, o reforço de relações de conjugalidade genderizadas e assimétricas, a instrumentalização dos afetos para exercer dominação e controlo). A sociedade em geral não pode demitir-se do seu papel, sendo necessário desconstruir muitos dos discursos sobre o amor, partilhados e veiculados no dia-a-dia que, como vimos, têm utilidades específicas e podem ser utilizados para legitimar e tolerar práticas abusivas e violentas na intimidade.

\section{Referências}

Black, M., \& Weiz, N. (2003). Dating violence. Help-seeking behaviors of African American middle schoolers. Violence Against Women, 9, 187-206.

Borochowitz, D. Y. (2008). The taming of the Shrew: Batterres' constructions of their wives' narratives. Violence Against Women, 14, 1166-1180.

Caridade, S. (2011). Vivências intimas violentas. Uma abordagem científica. Coimbra: Almedina.

Caridade, S., \& Machado, C. (2006). Violência na intimidade juvenil: Da vitimação à perpetração. Análise Psicológica, 4, 485-493.

Carpenter, L. (1988). From girls into women: Scripts for sexuality and romance in Seventeen magazine, 1974-1994. Journal of Sex Research, 35, 158-168.

Dias, A. R., \& Machado, C. (2011). Amor e Violência na Intimidade: Da Essência à Construção Social. Psicologia \& Sociedade, 23, 496-505.

Fraser, H. (2005). Women, love, and intimacy "gone wrong": Fire, wind, and ice. Affilia, 20, 10-20.

Fraser, H. (2003). Narrating love and abuse in intimate relationships. British Journal of Social Work, 33, 273-290.

Hatfield, E. \& Rapson, B. L. (2005). Love and sex: Cross cultural perspectives. Oxford: University Press of America, Inc.

Jackson, S. (2001). Happily never after: Young women's stories's of abuse in heterosexual love relationships. Feminism Psychology, 11, 305-321. 
Makepeace, J. M. (1981). Courtship violence among college students. Family Relations, 30, 97-102.

Matos, M., Machado, C. Caridade, S. \& Silva, M.J. (2006). Prevenção da violência nas relações de namoro: intervenção com jovens em contexto escolar. Revista Psicologia: Teoria e Prática, 8, 55-76.

Maxwell, C, (2007). "Alternative" narratives of young people's heterosexual experiences in the UK. Sexualities, 10, 539-558.

McAdams. A. (1995). The Life Story Interview. Disponível em: http://www.sesp. northwestern.edu/docs/LifeStoryInterview.pdf

Perilla, J. L. (1999). Domestic violence as a human rights issue: The case of immigrant Latinos. Hispanic Journal of Behavioral Sciences, 21, 107-133.

Pirog-Good, M.A. \& Stets, J. E. (1989). Violence in dating relationships: Emerging social issues. New York: Praeger.

Puente, S. \& Cohen, D. (2003). Jealousy and the meaning (or nonmeaning) of violence. Personality and Social Psychology, 29, 449-460.

QSR International (2010). NVivo9. Disponível em: www.qsrinternational.com/ nvivo9.

Romkens, R. \& Mastenbroek, S. (1998). Budding happiness: Dynamics in relations of teenage girls who are abused by their boyfriends. In R. Klein (Ed.), Multidisciplinary perspectives on domestic violence (pp. 58-75). London: Routledge.

Saavedra, R. (2010). Prevenir antes de remediar: Prevenção da violência nos relacionamentos íntimos juvenis. Dissertação de Doutoramento em Psicologia, na especialidade de Psicologia da Justiça. Braga: Escola de Psicologia, Universidade do Minho.

Tang, C. S., Wong, D., \& Cheung, F. M. (2002). Social construction of women as legitimate victims of violence in Chinese societies. Violence Against Women, 8, 968-996.

Towns, A. \& Adams, P. (2000). "If I really loved him enough, he would be okay": Women's accounts of male partner violence. Violence Against Women, 6, 558-585 .

Vandello, J. A. \& Cohen, D. (2003). Male honor and female fidelity: Implicit cultural scripts that perpetuate domestic violence. Journal of Personality and Social Psychology, 84, 997-1010.

Vandello, J. A., Cohen, D., Grandon, R., \& Franiuk, R. (2009). Stand by your man: indirect prescriptions for honorable violence and feminine loyalty in Canada, Chile, and the United States. Journal of Cross-Cultural Psychology, 40, 81-104 .

Wekerle, C., \& Wolfe, D. A. (1999). Dating violence in mid-adolescence: Theory, significance, and emerging prevention initiatives. Clinical Psychology Review, 19, 435-456.

Wetherell, M. (1995). Romantic discourse and feminist analysis: Interrogating investment, power and desire. In S. Wilkinson \& C. Kitzinger (Eds.), Feminism and discourse (pp. 128-144), London: Sage.

Wetherell, M. (1988). Positioning and interpretative repertoires: conversation analysis and post-structuralism in dialogue. Discourse \& Society, 9, 387-412. 
Wetherell, M., \& Potter, J. (1988). Discourse analysis and the identification of interpretive repertoires. In C. Antaki (Ed.), Analysing everyday explanation: A casebook of methods (pp. 168-183). Newbury Park, CA: Sage.

Wiggins, S., \& Riley, S. (2011). Discourse analysis. In M. A. Forrester (ed.), Doing qualitative research in Psychology, a practical guide (pp.135-153), London: Sage.

Wilding, R. (2003). Romantic love and "getting married": Narratives of the wedding in and out of cinema texts. Journal of Sociology, 39, 373-389.

Wood, J. T. (2001). The normalization of violence in heterosexual romantic relationships: Women's narratives of love and violence. Journal of Social and Personal Relationships, 18, 239-261.

Wood, K., Maforah, F., \& Jewkes, R. (1998). He forced me to love him: Putting violence on adolescent sexual health agendas. Social Science Medicine, 47, 233-242. 